\title{
Formal Modeling of Service Session Management
}

\author{
M. van Le, B.J.F. van Beijnum, and B.L. de Goede \\ Department of Computer Science, \\ University of Twente, The Netherlands. \\ $\{$ le, beijnum,goede\}@cs.utwente.nl
}

\begin{abstract}
This paper proposes a concept to apply modeling tools to MultiProvider Telematics Service Management. The service architecture is based on the framework called ì Open Service Componentsî which serves as building blocks to compose end-to-end telematics services in terms of service components offered by different service providers. Our work presented in this paper contributes to the abstract way of modeling end-to-end Service Management using Architectural Description Language and an underlying Formal Description Language.
\end{abstract}

\section{Introduction}

Today telematics services are becoming increasingly complex. For instance, new services are being introduced by integrating existing services. Also, in the provisioning of a service session, many different 'service components' have to cooperate in order to establish the end-to-end service session to users. Moreover, instead of having the ability to manage individual service components, end-to-end service provisioning will require the management of the cooperation between these components in a service session. One of the complicating aspects is that in the provisioning of the end-to-end service, multiple providers are involved. Hence, inter-domain management is required. With the advent of user mobility and in-session seamless roaming capabilities new challenges in end-to-end service management are faced [1, 3, 4].

To deal with the complexity of service management, and to arrive at new management solution we envisage an increasing need for the application of existing (formal) modeling and analysis methods. In this paper we present the application of such a method and tools for a (simple) multimedia service provisioning scenario. In future work, specific management issues will be addressed for this and other more complex scenarios, specifically we will address service accounting issues.

The modeling and analysis method selected for this paper consists of the architecture description language (ADL) and a formal specification language (FSL). The ADL Darwin is used to express the service in terms of 'components' and the relations between them. To specify the behavior of each component, the formal specification language FSP (Finite State Processes) is being used. The Service Session Management model of the scenario considered basically specifies the coordination of activation, modification and termination needed for the end-to-end service session.

The remainder of this paper is organized as follows:

The original version of this chapter was revised: The copyright line was incorrect. This has been corrected. The Erratum to this chapter is available at DOI: 10.1007/978-3-540-45812-8_28

K.C. Almeroth and M. Hasan (Eds.): MMNS 2002, LNCS 2496, pp. 36-48, 2002.

(C) IFIP International Federation for Information Processing 2002 
Section 2 discusses a scenario of multi-provider service architecture based on ì Open Service Components Architecture Frameworkî. Section 3 describes Service Session Scenario and associated Management Model. Section 4 presents the modeling method applied. Section 5 presents the model and some preliminary analysis results of the service session scenario. Finally, section 6 provides with conclusions and outlooks on future work.

\section{A Service Architecture}

The idea of Open Service Component Architecture Framework (OSCAF) is based on operational relevance. The framework is based on the observation that end-to-end services are built from 'service components' [2]. The services offered are mandated by a Service Level Specification (SLS), which is an agreed technical specification of the offered service. This technical specification determines the offered functionality and quality of service characteristics (the SLS is possibly parameterized, thus controllable to some extent by users). The means to offer a service is through the use of service components. In OSCAF four different classes of service components are distinguished, these are:

- Connectivity Service Components - Connectivity service components provide the distant exchange of information between geographically dispersed points. Thus, CSCs cover a very broad range of components, varying from bit-pipes, data-links, host-to-host communication, reliable inter-process communication channels, and the exchange of application messages.

- Network Service Components - Network service components offer functionality additional to connectivity service components. Concrete examples of network service components are time dependent routing, number translation, closed user groups, DNS, authorization and authentication. It is possible that different actors provide connectivity service components and network service components.

- Enabling Service Components - The execution of Application Service components is being supported by Enabling Service components that provide features related to selection, visibility, accountability and other facilities like adapting shape and language to usersí needs.

- Application Service Components - Application service components maintain, generate and provide information or functional capabilities intended for users. Examples are Video, MP3, Web-pages etc. However, the range is much wider. For instance: e-mail, relational database, ticket reservation, virtual workspace and the like.

The open character of a decomposition as illustrated in Figure 1 is prerogative for seamless service interworking with other Service Providers. An integral approach of Telematics Service Component Management is to arrive at optimal cooperation of the mentioned classes of services. 


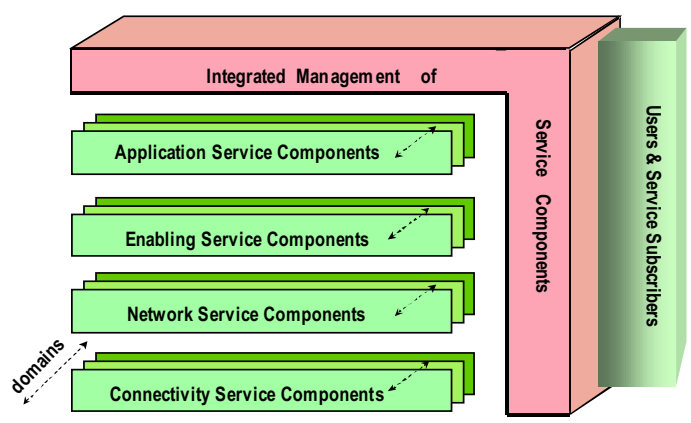

Fig. 1. Open Service Component Architecture Framework

\subsection{Service Session Life Cycle}

Three service life cycles can be identified in [2] in the context of operational lifetime, namely: Implementation Life Cycle, Subscription Life Cycle and Service Session Life Cycle. The implementation cycle involves: formulation of business plan, analyzing service characteristics, planning network resources, testing software, installing the service, etc. The subscription cycle is concerned with: contracts toward new service users, providing service users with relevant usage instruction, exchange of cost related data about service users with other domain, etc. The service session cycle involves the actual usage of services.

The service session life cycle consists of the following phases:

- Service Session Invocation - The service user invokes the Service Session Management by means of a service request. The requested service may be a composition different service components.

- Service Session Negotiation - This step enables the negotiation of appropriate service components to establish an end-to-end service session. The parameters of negotiation can be specified in a SLA (QoS, Price, etc.). The Service Session Management makes a selection of service component(s) to build up an end-to-end service session.

- Service Session Creation - Since the service session management is assumed to be capable to negotiate, select and drop service components offered by the negotiating service providers, this step confirms the participation of the selected service providers in the provisioning of a service session.

- Service Session Provision - Upon the reception of service component confirmation, service instances can be set-up and provisioned by the service providers. Parallel to service provisioning, service accounting can be started to account for the delivered service components. Further, service monitoring is essential to provide feedback to service providers about the delivered QoS, this information can have effect on the adjustment of the price that the user has to pay.

- Service Session Termination - Service session termination is the releasing of a session. Termination may be initiated by the service user or by a service provider. 


\section{A Service Scenario}

\subsection{Content Retrieval Service}

The process of service component delivery from a service provider to a service user may be divided into two aspects: service usage and service provisioning. Seen from the service usage, two important management information exchanges are generated: the service request from the user to the service provider and the service termination. Seen from the service the service provisioning, service management information must be interchanged between service providers to arrive at end-to-end service. We assume the participation of following actors:

- Mobile Network Operator (MNO)

- Application Service Broker (ASB)

- Content Providers (CPs)

- Connectivity Service Broker (CSB)

- Internet Service Provider (ISP)

\subsection{Content Retrieval Service Management}

Previous definition of Service Session Life Cycle raises a number of research questions concerning multi-provider service management. A few are listed below:

- How to define clearly the service management boundary within which a service component is being delivered?

- What management functions are required at each domain in order to cooperate with other domains?

- What kind of information needs to be exchanged at each step during the session life cycle?

- How can the coordination of local management functions be organized in an endto-end service management context?

In principle, two management models from the two extreme ends of multi-provider service management spectrum are conceivable: cascade and hierarchical service management.

Cascade service management is a management structure where userís service invocation is (re)directed to a content provider and the content provider figures out how to provision the requested service without further interaction with other involved actors. A good example of cascade service management is the current ì best effortî Video-on-Demand (VoD) service through the Internet. In most of the cases, the content provider injects an amount of packets into the network and these have to find their way to the next hop until they reach the end terminal. Cascade service management does not concern about the dependency of service components as a whole and the end-to-end service session management.

Hierarchical service management is a management structure where the handling of service invocation is processed and monitored. Contrary to the former, hierarchical service management has an end-to-end significance concerning service provisioning and the dependency of service component management functions. Other management 
structures are certainly possible. However, for a comprehensive presentation of our modeling approach, a hierarchical management structure will be discussed further in detail.

The service management topology illustrated in Figure 2 reflects the management architecture to be modeled in section 5. Three classes of management function are distinguished:

1. Component Management Function (CMF) represented by a dot: components having this class of management function can only act as managed entity.

2. Sub-Integral Service Management Function (sub-ISMF) represented by a square with an internal dot: components having this class of management function can act as managed entity as well as managing entity.

3. Integral Service Management Function (ISMF) represented by a filled square: component having this class of management function always acts as managing entity.

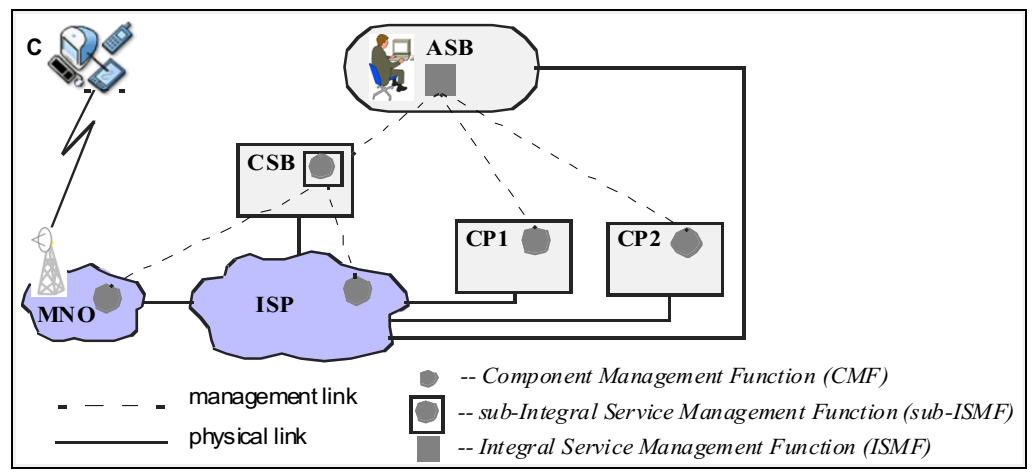

Fig. 2. Service Management Topology

In addition, Table 1 provides brief descriptions of the management functions and management information exchanged between managing en managed entities. The table describes how components interact and what service session management information should be exchanged.

In the chosen management model, ASB is assumed to have the information about which CP it should contact. ASB negotiates the requested content and the corresponding QoS level with both CP1 and CP2. There is a case where both CP1 and CP2 agree to provide the service component, then ASB will need to make a choice between one of the two service components offered. This situation is conceivable in practice when the prices of the service offered by CP1 and CP2 differ. The Service Component Provisioning is managed at local level, this means that if an actor confirms to the integral- or sub-integral management that the requested service component can be provided and service component creation confirmation message is received from the integral- or sub-integral management, then the actor must ensure a continuous provisioning of the service component (e.g. the final mapping of service confirmation message to network elements). These kinds of local management functionality are treated as ì internalî management activities of a service component, which are not relevant for the modeling of service session management. 


\begin{tabular}{|c|c|c|c|}
\hline Component & Management Function & $\begin{array}{c}\text { Management Informa- } \\
\text { tion Exchange }\end{array}$ & $\begin{array}{c}\text { Interact } \\
\text { with }\end{array}$ \\
\hline $\begin{array}{l}\mathrm{O} \\
\mathrm{C}\end{array}$ & $\begin{array}{l}\text { - send service request } \\
\text { - terminate service }\end{array}$ & $\begin{array}{l}\text { - content M + Q1 or Q2 } \\
\text { - termination message }\end{array}$ & $\begin{array}{l}-\mathrm{ASB} \\
\text { - ASB }\end{array}$ \\
\hline ASB & $\begin{array}{l}\text { - negotiate the requested con- } \\
\text { tent and the corresponding } \\
\text { QoS level } \\
\text { - negotiate the required net- } \\
\text { work resource a the end-to-end } \\
\text { transmission of the content } \\
\text { - select service components } \\
\text { and integrate these to obtain an } \\
\text { end-to-end application service } \\
\text { - inform C if the requested ser- } \\
\text { vice can be delivered or not } \\
\text { - create connectivity and ap- } \\
\text { plication service provisioning } \\
\text { - abort service provisioning } \\
\text { when needed } \\
\text { - terminate service }\end{array}$ & $\begin{array}{l}\text { - content M+QoS level } \\
\text { - QoS, source CP1 and } \\
\text { CP2 } \\
\text { non } \\
\text { - service confirmation mes- } \\
\text { sage } \\
\text { - service creation message } \\
\text { - service return message } \\
\text { - service termination mes- } \\
\text { sage }\end{array}$ & $\begin{array}{l}-\mathrm{CP} 1 \text { and } \\
\mathrm{CP} 2 \\
-\mathrm{CSB} \\
\text { non } \\
-\mathrm{C} \\
-\mathrm{CSB}, \mathrm{CP} 1 \\
\text { or } \mathrm{CP} 2 \\
\text { - CSB, CP1 } \\
\text { or } \mathrm{CP} 2 \\
\text { - CSB and } \\
\mathrm{CP} 1 \text { or } \mathrm{CP} 2\end{array}$ \\
\hline $\begin{array}{c}\bigcirc \\
\mathrm{CP} 1, \mathrm{CP} 2 \\
\end{array}$ & $\begin{array}{l}\text { - respond to ASB if the re- } \\
\text { quested content and the corre- } \\
\text { sponding QoS is available }\end{array}$ & - content $\mathrm{M}+\mathrm{Q} 1$ or $\mathrm{Q} 2$ & - ASB \\
\hline CSB & $\begin{array}{l}\text { - negotiate network resource to } \\
\text { destination C } \\
\text { - negotiate network resource } \\
\text { from source CP1 and CP2 } \\
\text { - respond if the requested end- } \\
\text { to-end connectivity can be } \\
\text { provided or not } \\
\text { - create connectivity service } \\
\text { provisioning }\end{array}$ & $\begin{array}{l}\text { - service negotiation mes- } \\
\text { sage } \\
\text { - datin1, datin2, Q1 and Q2 } \\
\text { - service confirmation mes- } \\
\text { sage } \\
\text { - service creation message }\end{array}$ & $\begin{array}{l}\text { - MNO } \\
\text { - ISP } \\
\text { - ASB } \\
\text { - MNO and } \\
\text { ISP }\end{array}$ \\
\hline $\mathrm{MNO}$ & $\begin{array}{l}\text { - respond to CSB if the re- } \\
\text { quested connectivity service } \\
\text { can be provided or not }\end{array}$ & $\begin{array}{l}\text { - service confirmation mes- } \\
\text { sage }\end{array}$ & - CSB \\
\hline ISP & $\begin{array}{l}\text { - respond to CSB which con- } \\
\text { nectivity service can be pro- } \\
\text { vided }\end{array}$ & $\begin{array}{l}\text { - service confirmation mes- } \\
\text { sage, Q1 or Q2, datin1 or } \\
\text { datin2 }\end{array}$ & - CSB \\
\hline
\end{tabular}

Table 1. Management Functions and Management Information Exchange 


\section{Modeling Method and Tools}

\subsection{Modeling Methodology}

State of the Art formal modeling methods can be applied to the previously presented service scenario and its management. More recently Architectural Description Languages have emerged. In review, the modeling concepts and tools relate as shown in Figure 3.

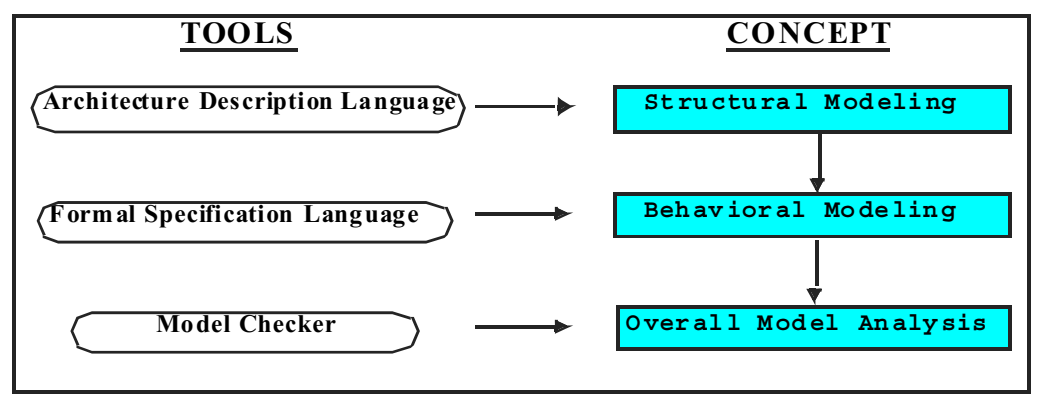

Fig. 3. The Modeling Concept

First, an Architecture Description Language (ADL) is used to express the structural aspect of a service architecture. The structural modeling step describes entities involved in an architecture and how they are connected to each other, through which interface, etc. A structural model should represent the topology of service relationships between the involved actors. Moreover, a structural model should contain the following information:

- Which actor is responsible for which class of service component;

- Through which interface should a certain service be provided;

- How end-to-end service is provisioned;

- Clear distinction of different class of interactions (e.g. basic signaling, accounting signaling, data stream, etc.);

In the area of software engineering, ADLs have been identified as promising approach to bridge the gap between requirements and implementation in the design of complex systems [5]. A few well-known ADLs among system designers are: Darwin, Meta-H, Rapide, Wright. In addition, some of the ADLs support the capability to specify dynamic structures, a capability needed to capture roaming users.

Second, the structural model is enriched with a behavior specification using a Formal Specification Language (FSL) that enables the behavioral modeling. The behavior of each component is specified in terms of process algebra.

Third, to gain confidence in the correctness of the system, Model Checker is used once the behavioral model has been specified. Model checking techniques are especially aimed at the verification of reactive, embedded systems, i.e. systems that are in constant interaction with the environment. These techniques allow the designer to ver- 
ify that a mathematical model of a system satisfies logical properties depicting correct system behavior [6]. The followings summarize important aspects of model analysis:

- Consistency: does the behavior of an entity conform the protocols, which are being used to interact to other entities?

- Completeness: is any part missing in the system? (or, could we remove some parts and still being able to make sure that the system still function properly?)

- Refinement: can one architecture be substituted for other?

- Verification: does an implementation conform the architecture?

- Performance and Reliability: can the server handle the expected demand? will average response time meet the requirements? which entity is the bottleneck? how would server/database replication affect the serverís performance?

The model-checking step does not only help to analyze the behavioral model, it also provides good comprehension of the system in order to arrive at the management design.

\subsection{Languages and Tools}

Most of ADLs have some formal semantics, which allows model checking. Darwin uses Finite State Processes (FSP), whereas Wright uses Communicating Sequential Processes (CSP). Both FSP and CSP are formal specification languages. Meta-H and Rapide use their own specification languages [7, 8, 9, 10]. Although limited in the number of states that can be captured and analyzed, Darwin/FSP is easy to use and therefore well suited as initial choice for this study.

Darwin Architecture Description Language has been successfully applied in the area of software engineering to describe the structure of distributed telematics systems [11]. Darwin is a declarative configuration language, which may be used to describe the overall architecture of a distributed system as a hierarchical composition of interconnected components. Each Darwin component is an instance of a component type. The component interfaces are defined in terms of provided or required service. Components are connected by a fixed set of connector types. The effect of binding a provided service with a required service that corresponds to the composition of the subcomponents, and a configuration corresponds to the parallel composition of the components. Darwin has the ability to specify dynamically changing architectures: new components may be created as the result of the invocation of a particular kind of provided service $[12,13,14]$.

To obtain the Darwin description of the Content Retrieval Service as illustrated in Figure 2, we make use of the Software Architect's Assistant (SAA) [15], a visual programming tool that supports the construction of distributed programs through the design of their architectures. SAA generates Darwin description from a graphical representation of the system.

Given the overall structure specified in Darwin, this Darwin description can be parsed to an FSP specification using FSP's composition constructs. The behavior of each component can be specified in FSP. The combination of the two gives the entire system specification in FSP. For overall model analysis the tool LTSA is used [16]. 


\section{Modeling of Service Management}

\subsection{Modeling of the Structure of the Content Retrieval Service}

From the structural view, each involved actor is modeled as an independent component. Interaction between two components takes place through ì bindingî. Distinction between two types of bindings is made explicitly, namely: signaling binding and data binding. Further, we chose to model unidirectional bindings for clarity purposes of management information exchanging.

Figure 4 depicts the graphical representation of the service architecture and the corresponding Darwin description. Management information exchange is enabled by unidirectional signaling bindings, ì sig1_nameî indicates an initiated interaction of a component, whereas ìsig1_nameî indicates an absorbed interaction of that same component.

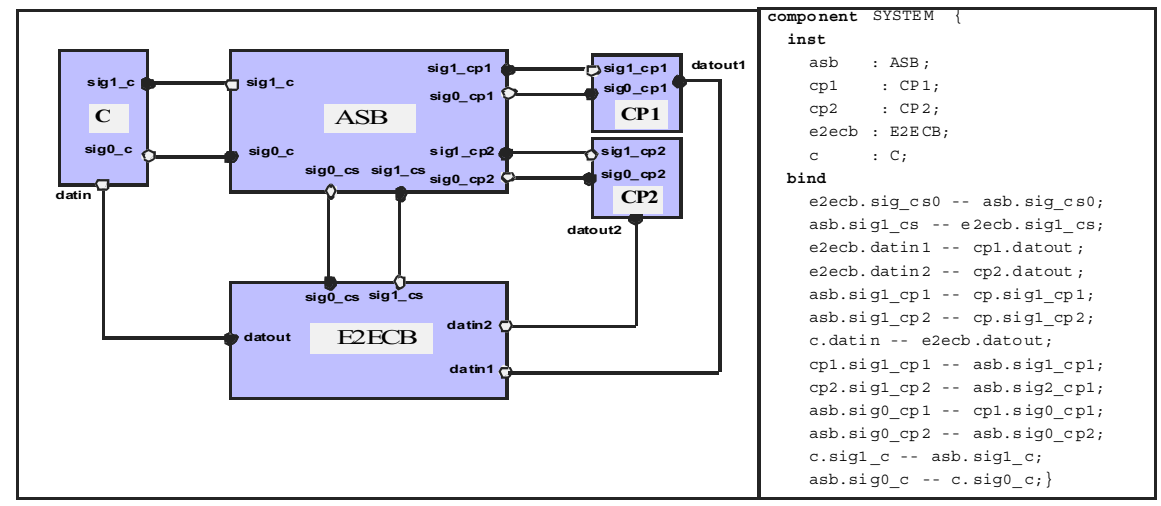

Fig. 4. Compositional Service Architecture

The refinement of the end-to-end Connectivity Broker component (E2ECB) is shown in Figure 5. The choice to model CSB, MNO and ISP as sub-components has to do with the separation of concern in terms of provided service components. In doing so, ASB delegates a portion of management tasks to CSB that needs to take care of the end-to-end connectivity service.

The CP1 and CP2 offer their application services physically through data interfaces datin1 and datin2, respectively. Once the data arrives at ISP, it is transmitted through one single data binding in the direction of MNO and then $\mathrm{C}$.

To summarize, the model contains the following parameters that govern the number of end-to-end service provisioning scenarios and therefore the number of states:

- 1 content in a single segment: $\mathrm{M}$

- 2 content providers: CP1 and CP2

- 2 QoS levels: Q1 and Q2

- 2 data interfaces: datin1 and datin2 


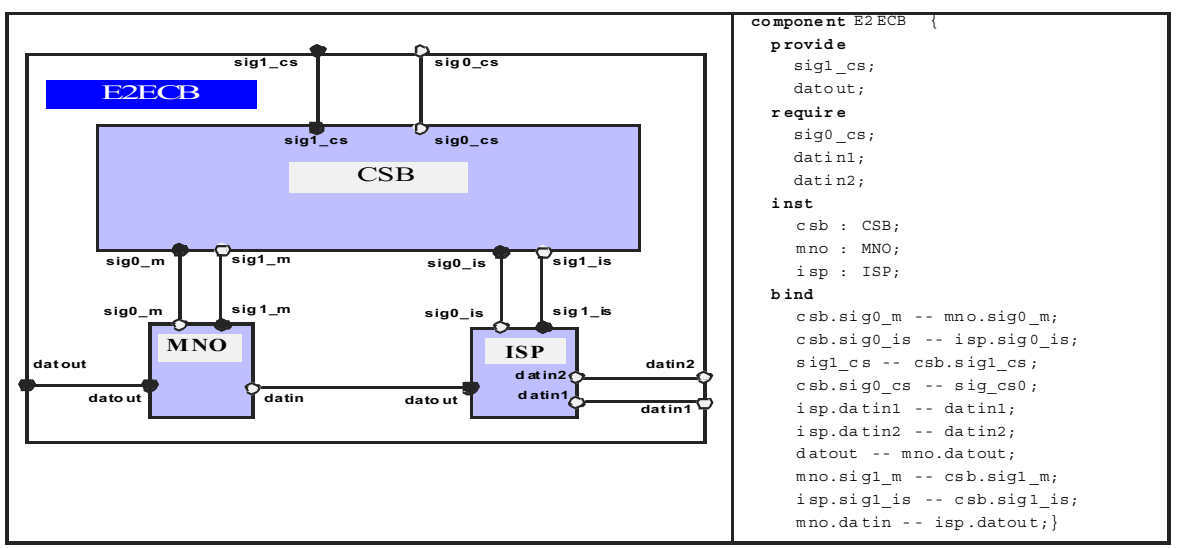

Fig. 5. Refinement of E2ECB component

\subsection{Specifying the Behavior of the Service Components}

The system behavior is modeled as a Labeled Transition System (LTS) with shared actions to synchronize processes. It is important to keep in mind the recurrence of the processes running in a system during the behavioral modeling phase, where ì lifeî is created within each primitive ${ }^{1}$ component. In terms of finite states processes, once a service session life cycle is terminated, all processes must return to the initial state.

The behavioral model of CP1 is shown in Figure 6 together with its corresponding FSP specification. The result of the systemís overall behavior is a composite LTS:

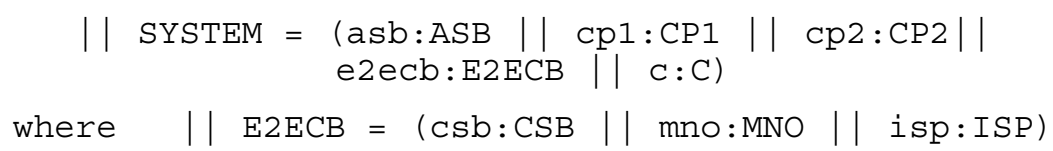

The behavior of primitive component CP1 is relatively simple compared to other components in the model. CP1 is illustrated here as example to provide an idea about how the behavior of a primitive component can be described and graphically displayed as a finite state machine using LTSA.

LSTA provides two principle options to analyze a system: safety- and progress analysis:

- Safety Analysis checks systemís deadlock, which is generally a bad state from which no further actions can be executed. Deadlock might occur in case a component cannot finish it session life cycle before the start of another session.

- Progress Analysis checks systemís property to ensure that whatever state the system is in, there is always the case that a specified action will eventually be executed.

In addition to basic analysis options, one can also check system ës property with some pre-defined requirements. For instance, the responsiveness property of an accounting system ensures that accounting must stop whenever provision failure occurs.

\footnotetext{
${ }^{1}$ without decompositions capability
} 


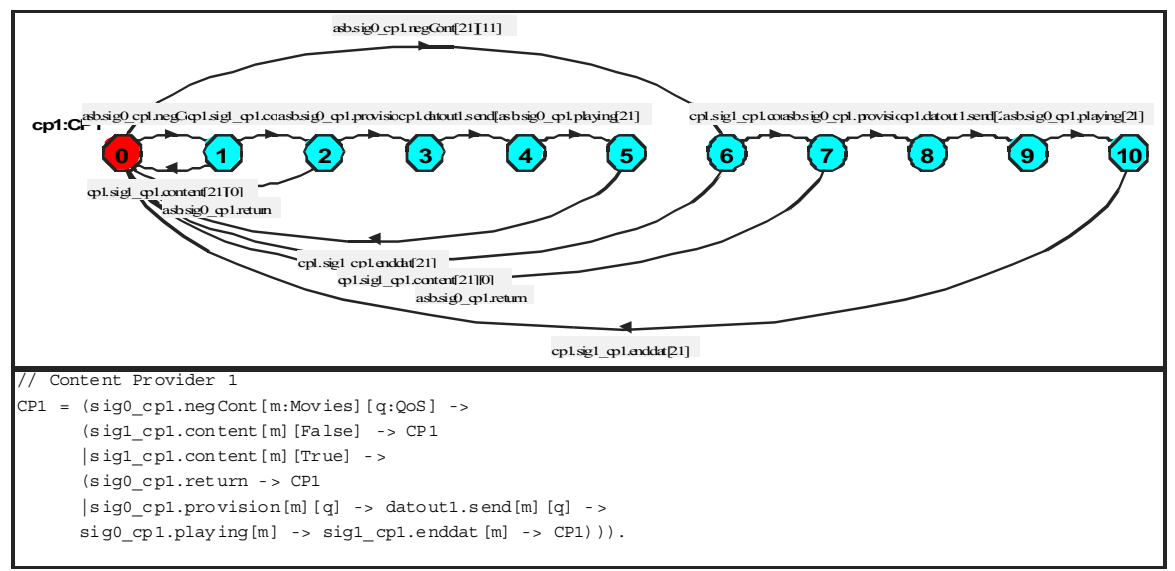

Fig. 6. Content Providerís behavioral model

In order to gain confidence in the correctness of the model, we first run the reachability analysis to check for deadlock in the system. A summary of the reachability analysis is given in Figure 7.

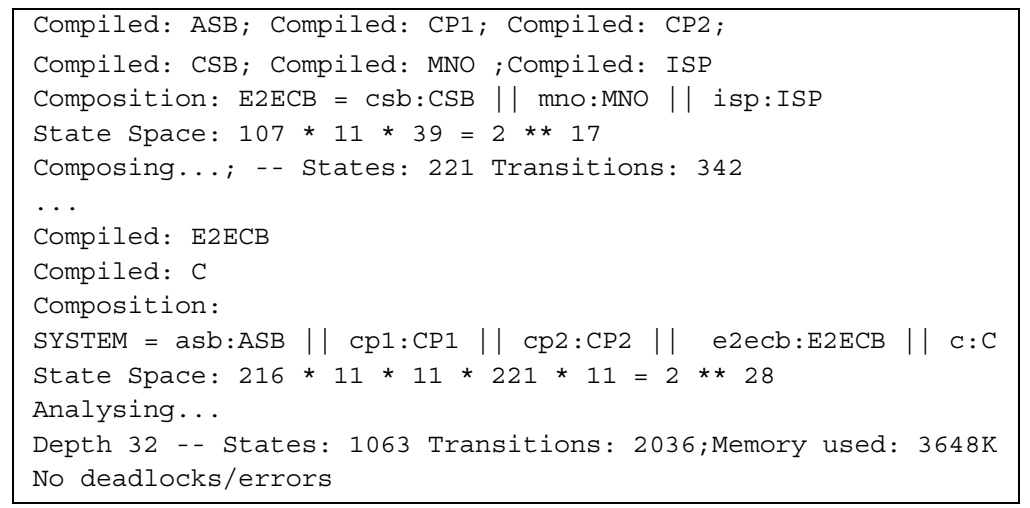

Fig. 7. Reachability Analysis

As indicated, there is no deadlock in the system. However, reachability does not guarantee that a systemís behavior completely meets the systemís requirements. Therefore, all possible service scenarios must be examined with respect to expected management functionalities of each component. According to the systemís degrees of freedom, ASB must manage in total 64 operational service scenarios, namely:

[M:1]x[QoS:2]x[CP:2]x[Availability:2]x \{[DataInterface:2]x[QoS:2]x[Availability:2] $\}=64$

Where [Availability] is a YES or NO response of a managed entity in responding to a managing entity about the availability of the requested service component. 


\subsection{Example of End-to-End Service Provisioning}

As mentioned previously, the behavioral modeling results in 64 operational service scenarios. Figure 8 provides the message sequence diagram of a scenario to illustrate how the Service Session Life Cycle mentioned in section 2 can be followed to obtain an end-to-end service provisioning.

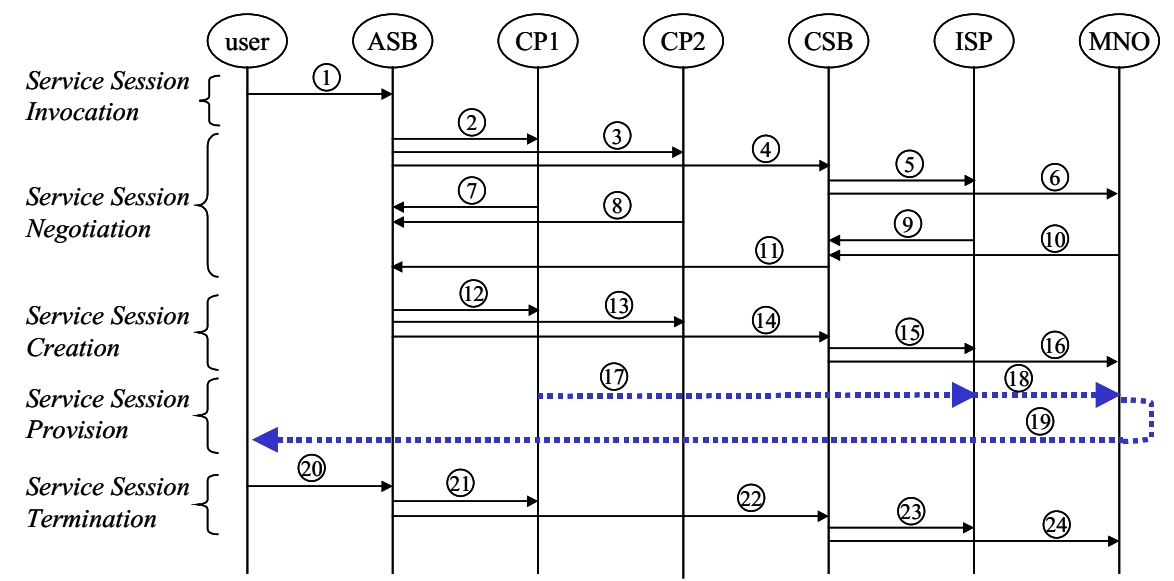

Fig. 8. Message Sequence Diagram of a service-provisioning scenario

- Step 1 ñ The user invokes a service.

- Step 2 and $3 \tilde{n}$ ASB negotiates the requested content and the corresponding QoS.

- Step 4 ñ ASB negotiates the required network resource for the end-to-end transmission of the content.

- Step 5 and 6 ñ CSB negotiates network resource at ISP and MNO

- Step 7 and $8 \tilde{\mathrm{n}} \mathrm{CP} 1$ and CP2 respond positively to ASB.

- Step 9 and 10 ñ ISP and MNO respond positively to CSB.

- Step 11 ñ CSB responds positively to ASB about the availability of the end-to-end connectivity service.

- Step $12 \tilde{\mathrm{n}}$ ASB creates the application service component offered by CP1.

- Step 13 ñ ASB informs CP2 that it the offered service component is dropped.

- Step 14 ñ ASB creates the end-to-end connectivity service offered by CSB.

- Step 15 and 16 ñ CSB creates the connectivity service components offered by ISP and MNO.

- Step 17 to $19 \tilde{\mathrm{n}}$ The actual end-to-end service is being provisioned.

- Step 20 ñ The user terminates the ongoing service.

- Step 21 and 22 n ASB terminates the application and end-to-end service components.

- Step 23 and 24 ñ CSB terminates the connectivity service components. 


\section{Conclusions and Future Work}

In our study we focus on the service management aspects, we abstract from the physical relations by looking at the service relations between the actors. We decompose telematics service management in a multi-provider environment in such a way that application of formal method results in an operational relevant behavioral model. The proposed concept serves as a basis for further application of formal method in the area of Service Management to investigate crucial properties of end-to-end Service Management Systems in order to arrive at a secure and optimal management system design.

As far as the future work is concerned, we aim at exploring the possibility to include mobility aspects in the modeling of multi-domain Service Management. As mentioned, Darwin has the ability to specify dynamically changing structures, which can be useful to describe the mobility of the customer when roaming from one to another domain and the systemís behavior as a result of the userís mobility. Future extensions of the work presented here include also the modeling of multi-domain Accounting Management and property verification of service session management and its associated session accounting management.

\section{Reference}

1. Shingo Ohmori, ì The concept of future generation mobile communication based on broadband access technologyî, IEEE Communication Magazine, Dec. 2000.

2. B.L. de Goede, ì Operational Management of Telematics Systems and Servicesî, ISBN: 90365-1709-5, Dec. 2001.

3. Lewis, D.A.: "A framework for the development of service management systems for the open service market", PhD thesis, UCL, Mar. 2000.

4. Q. Kong et al: ì A Management Framework for Internet Servicesî, CiTR technical journalVol.3, 1998.

5. J. Kramer, J. Magee, ì Explosing the skeleton in the Coordination Closetî, Proc. of the 2nd International Conference on Coordination Models and Languages, Sept. 1997.

6. R. Allen: ì A Formal Approach to Software Architecturê̂, PhD thesis, 1997.

7. ì Rapide Overviewî, http://pavg.stanford.edu/rapide/overview.html

8. îThe Wright Architecture Description Languageî, http://www-2.cs.cmu.edu/afs/cs/ project/able/, Canergie Mellon - School of Computer Science,1998.

9. ì Darwin - An Architecture Description Languageî, http://www.doc.ic.ac.uk/ jsc/research/, Dept. of Computing, Imperial College, Apr. 1997.

10. ì Meta-H Language and Toolsî, http://www.htc.honeywell.com/ projects/dssa/dssa tools.

11. H. Fossa: ì Implementing Interactive Configuration Management for Distributed Systemsî, International Conference on Configurable Distributed Systems, Annapolis MD, May 1996.

12. J.Kramer: ì Analysing Dynamic Change in Software Architectures - A Case Studyî ; 4th International Conference on Configurable Distributed Systems, Annapolis, May 1998.

13. N. Dulay, ì Darwin Refererence Manualî, Dept. of Computing, Imperial Collegê̂, 1994.

14. J. Magee, N. Dulay, J. Kramer, ì Specifying Distributed Sofware Architectureî, Proc. of the 5th European Software Engineering (ESECí95), Sept. 1995.

15. K. Ng, et al: ì A Visual Approach To Distributed Programmingî, in Tools and Environments for Parallel and Distributed Systems, A. Zaky and T. Lewis (Eds.), Kluwer Academic Publishers, Feb. 1996.

16. J. Magee, J. Kramer: ì Concurrency: State Models \& Java Programsî, Wiley, 1999. 